Supporting information

\title{
The influence of small organic molecules on coagulation from the perspective of hydrolysis competition and crystallization
}

Xuejia Zhang,b, Nigel Grahamc, Lei Xuc, Wenzheng Yu ${ }^{\mathrm{a}}{ }^{*}$, John Gregory ${ }^{\mathrm{d}}$

${ }^{a}$ State Key Laboratory of Environmental Aquatic Chemistry, Research Center for Eco-Environmental Sciences, Chinese Academy of Sciences, Beijing 100085, China

b University of Chinese Academy of Sciences, Beijing 100049, China

${ }^{c}$ Department of Civil and Environmental Engineering, Imperial College London, South Kensington Campus, London SW7 2AZ, UK

${ }^{\mathrm{d}}$ Department of Civil, Environmental and Geomatic Engineering, University College London, Gower Street, London WC1E 6BT

xjzhang_st@rcees.ac.cn,n.graham@imperial.ac.uk, lxu@rcees.ac.cn, wzyu@rcees.ac.cn, j.gregory@ucl.ac.uk 


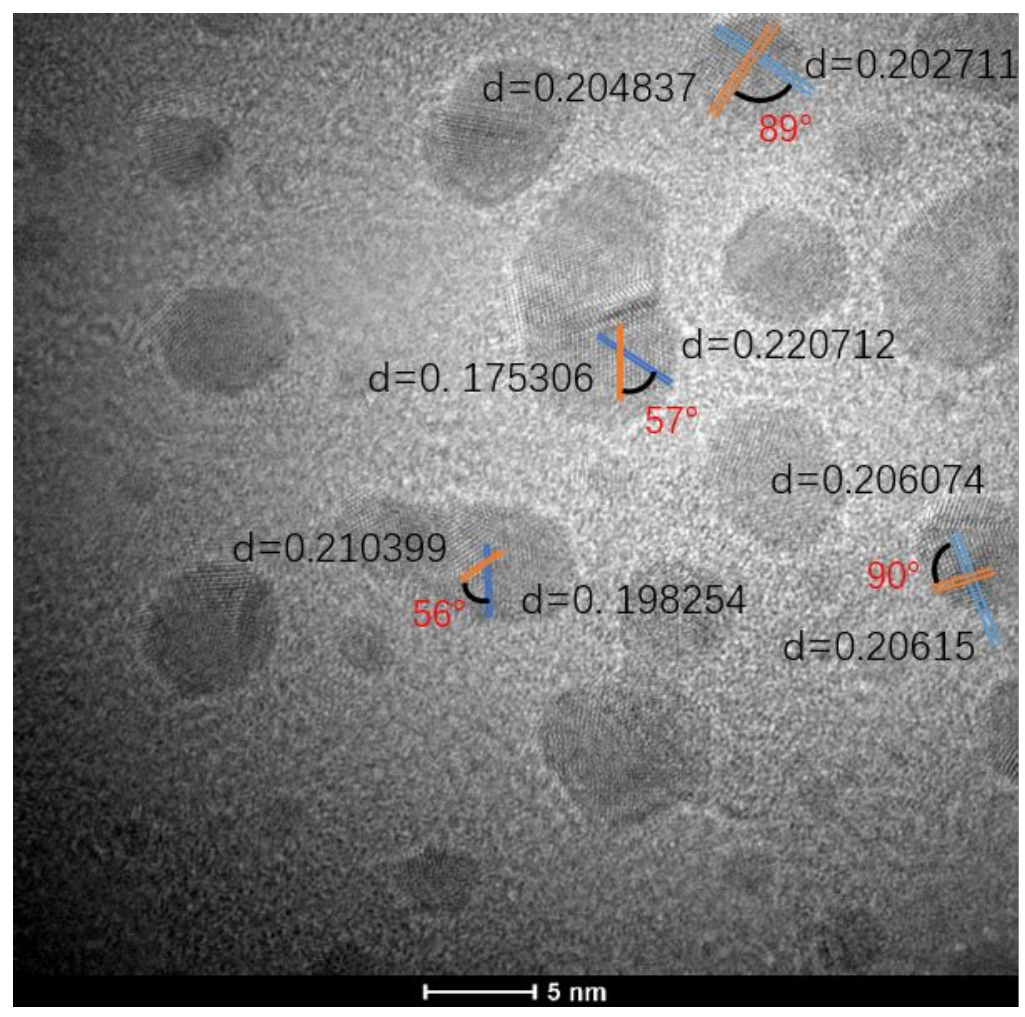

Figure S1 Transmission electron microscope (TEM) images of broken flocs with citric acid $(0.05 \mathrm{mM})$ at $\mathrm{pH}$ 7. The width and included angle of nanocrystals are indicated. 
Table S1 Physico-chemical properties of the five LMW organic compounds

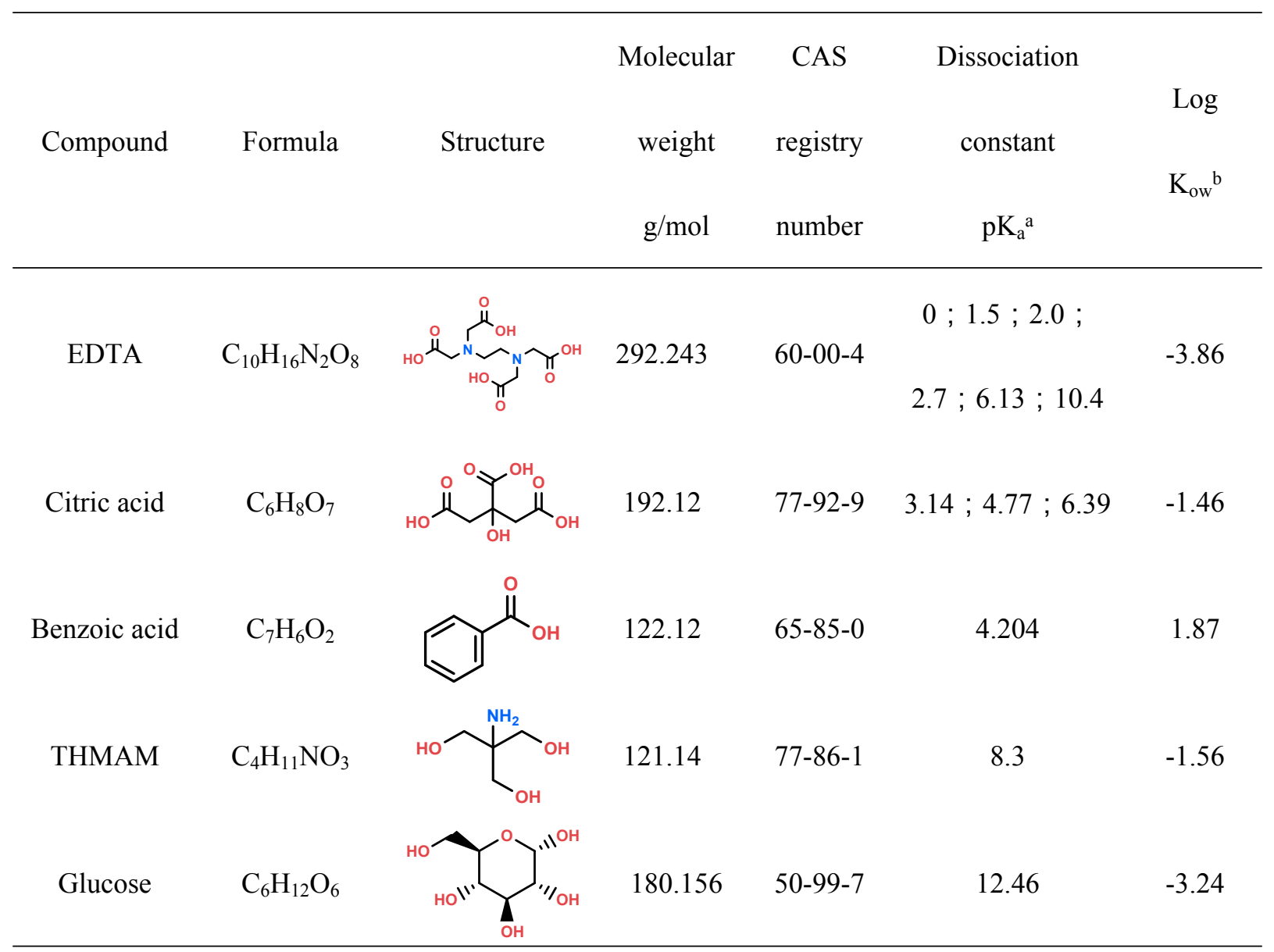

a. CRC Handbook of Chemistry and Physics. CRC press, BocaRaton, Florida. USA. 79th edn 1998-1999

b. Chemspider, 2008. Chemical data base search. Accessed December, 2008 Available at http://www.chemspider.com/Search.aspx 